\title{
The effects of intrathecal ketamine on improving sensory-motor function in a rat model of compression spinal cord injury
}

\author{
Sajad Fakhri ${ }^{1}$ iD, Fatemeh Abbaszadeh² iD, Ramin Pouriran ${ }^{3}$, Masoumeh Jorjani $^{2,4 *}$ (iD) \\ 1. Pharmaceutical Sciences Research Center, Health Institute, Kermanshah University of Medical Sciences, Kermanshah, Iran \\ 2. Neurobiology Research Center, Shahid Beheshti University of Medical Sciences, Tehran, Iran \\ 3. School of Medicine, Shahid Beheshti University of Medical Sciences, Tehran, Iran \\ 4. Department of Pharmacology, School of Medicine, Shahid Beheshti University of Medical Sciences, Tehran, Iran
}

\begin{abstract}
Introduction: The major secondary complications of spinal cord injury (SCl) are neuropathic pain and motor dysfunction, which remained medical challenges for clinicians. Due to the major role of glutamate in excitotoxicity and central sensitization, the present experiment was to evaluate the effects of ketamine (KET), an n-methyl-D-aspartate (NMDA) receptor blocker, on sensory-motor functions in a rat model of clip compression $\mathrm{SCl}$.
\end{abstract}

Methods: Wistar rats were divided into sham, SCI and KET-treated groups. The sham group received laminectomy without any compression lesion. KET and $\mathrm{SCl}$ groups were subjected to severe compression injury for $1 \mathrm{~min}$ with an aneurysm clip and then treated with KET $(10 \mathrm{mg} / \mathrm{kg})$ or $5 \%$ dimethyl sulfoxide (as vehicle), respectively. The rats were assessed by pain-related and motor behavioral tests inclusive of von Frey, acetone drop, hot plate, inclined plane and Basso-Beattie-Bresnahan on day 0 prior to the injury and the $7^{\text {th }}, 14^{\text {th }}, 21^{\text {st }}$ and $28^{\text {th }}$ days following SCl.

Results: KET group compared with the SCI group showed a significant decline in the mechanical allodynia on the $21^{\text {st }}$ and $28^{\text {th }}$ days, and in cold allodynia from the $1^{\text {st }}$ week to the $4^{\text {th }}$ week post-injury. KET treatment improved the motor function but not weight loss and auricle temperature rise during the 4 weeks of follow up from the $1^{\text {st }}$ week until the $4^{\text {th }}$ week.

Conclusion: It was ultimately attained that the advantageous effects of intrathecal KET on sensory-motor dysfunction of SCI rats could provide new approaches for KET as a neuroprotective agent toward clinical applications.

http://dx.doi.org/10.32598/ppj.24.2.20

\section{Keywords:}

Ketamine;

Spinal cord injury;

Neuropathic pain;

Motor activity;

Rat

\section{* Corresponding author:}

M. Jorjani

Email:

msjorjani@sbmu.ac.ir

Tel: +98 (21) 22429768

Received 21 July 2019;

Received in revised form 25

January 2020; Accepted 12

February 2020

\section{Introduction}

Spinal cord injury (SCl) is a major complication of traumatic spinal damage, causing motor disturbance and central neuropathic pain. Neuropathic pain has a prevalence rate of approximately $50 \%$ in $\mathrm{SCl}$ 
patients, which affects the life expectancy, cost burden and causes a diminished quality of life. Development of allodynia and hyperalgesia are clinical hallmarks of post-SCI neuropathic pain (Siddall and Middleton, 2015). Pharmacological treatments are often not useful for post-SCI neuropathic pain and motor dysfunction. Further, these complications are usually resistant to medications. Thus, it is important to develop novel and effective treatments for post-SCl sensory-motor dysfunction.

Following $\mathrm{SCl}$, the elevation of excitatory amino acids leads to prolonged activation of spinal cord neurons causing the spread of nociception and neuropathic pain. According to data, the development and maintenance of neuropathic pain could be influenced by n-methyl-d-aspartate receptors (NMDAR) (Zhou et al., 2011). Ketamine (KET) as a potent sedative, amnestic, analgesic and anesthetic agent blocks NMDAR and in turn its down-stream neuroinflammatory signaling pathways. Thus, it could be considered as a promising neuroprotective agent for SCI complications (Kose et al., 2012). The antinociceptive effects of KET have been shown in several preclinical studies. Ketamin's chronic painrelieving properties have been reported in neuropathic pain models and inflammatory conditions. The KET antidepressant effects show that KET affects both the sensory-discriminative system and the affective-motivational components of pain (Radvansky et al., 2016).

In clinical situations, pain treatment by KET has been reported on the management of nerve injury in oncologic diseases (Domino, 2010), morphineresistant cancer pain (Schwartzman et al., 2009), post-herpetic neuralgia (Sawynok and Zinger, 2016) and post-injury pain (Domino, 2010). For conditions with neuropathic pain features with an identifiable nerve injury such as $\mathrm{SCl}$, there is still inconclusive evidence for the effectiveness of KET. At the spinal level, KET has shown an analgesic effect by downregulating glial fibrillary acidic protein (GFAP) expression and inhibiting astrocyte activation (Mei et al., 2009).

Intravenous (IV) KET reduced post-injury pain and improved allodynia plus hyperalgesia in two randomized, double-blind placebo control studies in patients with neuropathic pain (Mestre et al., 1994). On the other hand, there have not been sufficient reports to show the effects of intrathecal (IT) KET in pain and particularly motor outcomes in the context of $\mathrm{SCl}$. To the best of our knowledge, this is the first investigation regarding the possible long-lasting motor performance-enhancing and analgesic effects of IT KET on cold, thermal and mechanical pain along with weight and temperature changes as common complications post-SCl. This may lead to the introduction of a therapeutic agent towards clinical applications.

\section{Materials and methods}

\section{Animals}

In total, 21 adult rats (male Wistar, 250-300g) were provided. The rats were housed in 4-5 per standard cages under a $12 \mathrm{~h} / 12 \mathrm{~h}$ light-dark cycle regiment. They were maintained at a $24 \pm 2^{\circ} \mathrm{C}$ temperaturecontrolled room with free access to food and water for at least 10 days prior to the study. The surgical procedures were performed using aseptic techniques. The entire procedure was approved by the institutional animal care and use committee in Shahid Beheshti University of Medical Sciences (IR.SBMU.REC.1396, 321).

\section{Experimental groups}

Randomly, twenty-one animals were divided into 3 experimental groups of sham, $\mathrm{SCl}$ and KET ( $\mathrm{n}=7$ per group). The sham group received only laminectomy. The $\mathrm{SCl}$ group and KET group underwent laminectomy and compression injury then treated by IT injection of $5 \%$ dimethyl sulfoxide (DMSO) as vehicle and KET 30min after injury, respectively. Sensory and motor function of animals were assessed by von Frey test, acetone drop test, hot plate test, Basso-Beattie-Bresnahan (BBB) test, inclined plane test, as well as body weight and auricle temperature changes on the $0,7^{\text {th }}, 14^{\text {th }}, 21^{\text {st }}$ and $28^{\text {th }}$ days following surgery.

\section{Compression spinal cord injury}

Deep anesthesia was made by intraperitoneal (IP) injection of $10 \mathrm{mg} / \mathrm{kg}$ xylazine and $80 \mathrm{mg} / \mathrm{kg}$ ketamine, before the surgery. The laminectomy of thoracic 8 (T8)-thoracic 9 (T9) was done following the incision of skin and muscle. The spinal cord was exposed using a micro rongeur (Fine Science Tools, USA), then it was compressed by an aneurysm clip (Aesculap, Tuttlingen, Germany, 90g) for $1 \mathrm{~min}$ (Fakhri et al., 
2018; Fakhri et al., 2019). The dura mater was left intact. After the surgery, the skin and muscle were sutured with 3-0 silk sutures; consequently, rats were allowed to recuperate on a $30^{\circ} \mathrm{C}$ heating pad. Cefazolin (40mg/kg IP) and $2 \mathrm{ml}$ normal saline (subcutaneously, SC) were administrated twice a day to prevent urinary tract infection and attain rehydration, respectively. The bladder in the rats was manually emptied twice a day up to reflex bladder emptying returned. The entire rats were kept under standard conditions in clean cages.

\section{Intrathecal drug injection}

KET (Ketalar®, Pfizer Inc., USA) powder was dissolved in a vehicle of $5 \%$ DMSO. The modified method of Mestre et al. (1994) was utilized for IT injection of KET and 5\% DMSO (as vehicle) following SCl (Burton et al., 1999). A 25-G needle was attached to the Hamilton syringe which was used for IT injection. Needle at a $45^{\circ}$ angle was inserted to the subarachnoid space between two adjacent vertebrae in the lumbar 6/5 level. Identifying the needle in the subarachnoid space was based on the existence of an immediate lateral tail movement that occurred following the penetration of the ligament flavum. The dosage of KET $(10 \mathrm{mg} / \mathrm{kg}$ ) (Walker et al., 2010) or $5 \%$ DMSO $(20 \mu \mathrm{l})$, was injected gradually over 10 s into the KET group as well as SCI group, once the needle was in the subarachnoid space. In order to stop the outflow of the medication, the syringe was kept for 10s more in the subarachnoid space.

\section{Behavioral assessment \\ Mechanical allodynia}

Mechanical allodynia was assessed using von Frey filaments. The lateral aspect of the plantar area of both paws was stimulated with an incremental series of 5 von Frey filaments (10, 15, 26, 60 and 100g). Each filament was applied five times with 5 s intervals. Paw licking, withdrawal, biting or flinching was expressed as a positive mechanical allodynia response. Positive responses three out of five in repetitive stimuli was considered as an allodynia threshold.

\section{Cold allodynia}

The acetone drop test was performed to assess cold allodynia. The animals were placed on the top of a wire mesh grid in acrylic cages to access their paws.
After a 45min acclimatization, approximately $100 \mu \mathrm{l}$ acetone applied from a distance of $2 \mathrm{~cm}$ to the plantar surface of the hind paw in order to test a cold stimulation reaction. If a rat withdrew its hind paw, a response was recorded, which was classified and scored as follows: no reaction (score 0), startle response without paw withdrawal (score 1), brief withdrawal of the paw (score 2), prolonged withdrawal of 5-30s (score 3), prolonged and repetitive withdrawal of 30 s with flinching and/or licking (score 4). This acetone test has been described as composing of chemical, cold and possibly mechanical stimulation. An observer tested cold allodynia in a blinded manner.

\section{Heat hyperalgesia}

A hot plate apparatus (Harvard apparatus, America, $45-52^{\circ} \mathrm{C}$ ) was used to measure analgesia. The animals individually were placed on a transparent Plexiglas chamber on a hot plate analgesia meter, then were examined for baseline latency to paw licking or jumping. Each rat was tested three times with an interval of $5 \mathrm{~min}$. The average of three replicates was reported as paw withdrawal latency. $A$ 60s cut-off was enforced to stop stimulating and prevent tissue injury.

\section{Locomotor activity}

Motor performance was evaluated in rats using an inclined plane and BBB tests. In the first test, each rat was placed on an adjustable wood plane $(60 \times 40 \mathrm{~cm})$ with changeable angles from $0^{\circ}$ (horizontal) to $60^{\circ}$ (3 times with $5 \mathrm{~min}$ intervals). The angle of the plane was increased gradually. Two blinded observers assessed the maximum angle in which the rats stayed stable for $5 \mathrm{~s}$ and the average angle was considered.

BBB locomotor scale was also used as the second test to evaluate the locomotor activity of rats. Briefly, two blinded examiners observed animals for $4 \mathrm{~min}$ which were placed in a wooden box $(90 \times 10 \mathrm{~cm})$. The BBB score was defined in the range of 0 (complete paralysis of both hind limbs) to 21 (standard walking) for all rats, prior to the surgery (day 0) and also on the $1^{\text {st }}, 7^{\text {th }}, 14^{\text {th }}, 21^{\text {st }}$ and $28^{\text {th }}$ days after the surgery. The mean value of the scores for both hind paws was calculated for the rats per time point in order to obtain only one movement value. 


\section{Weight difference}

In all three groups, the weight changes in rats were calculated using the following formula: weight difference $=\left(\right.$ animal's weight on the $7^{\text {th }}, 14^{\text {th }}$, $21^{\text {st }}$ and $28^{\text {th }}$ days- weight on day 0 (before the surgery))

\section{Auricle temperature}

A quickly responding Microlife infrared thermometer (NC-100) was used to determine rats' auricle temperature. The sensor was held at a distance of $5 \mathrm{~cm}$ over the dorsal aspect of the auricle surface temperature.

\section{Statistical analysis}

The data is indicated as the mean \pm SEM. By using Version 6.0 of the GraphPad Prism Program, the analysis was done. Repeated measures two-way analysis of variance (ANOVA) with Bonferroni posthoc analysis was performed for the comparison of the groups across all measuring times. A difference at $P<0.05$ was considered significant in all calculations.

\section{Results}

\section{Mechanical allodynia}

A significant result for the main effects was attained by two-way repeated-measures ANOVA which indicated: [group: $F(2,18)=21.51, P<0.001$, times: $F(4,72)=24.64, P<0.001$ and interaction: $F(8,72)=$ 3.808, $P=0.0009$ ] on right paw withdrawal threshold in von Frey test, and also the left paw withdrawal threshold of the groups $[F(2,18)=18.82, P<0.001]$, times $[F(4,72)=27.68, P<0.001]$, and interaction $[F(8,72)=3.31, P=0.0028]$. Despite the same paw

B

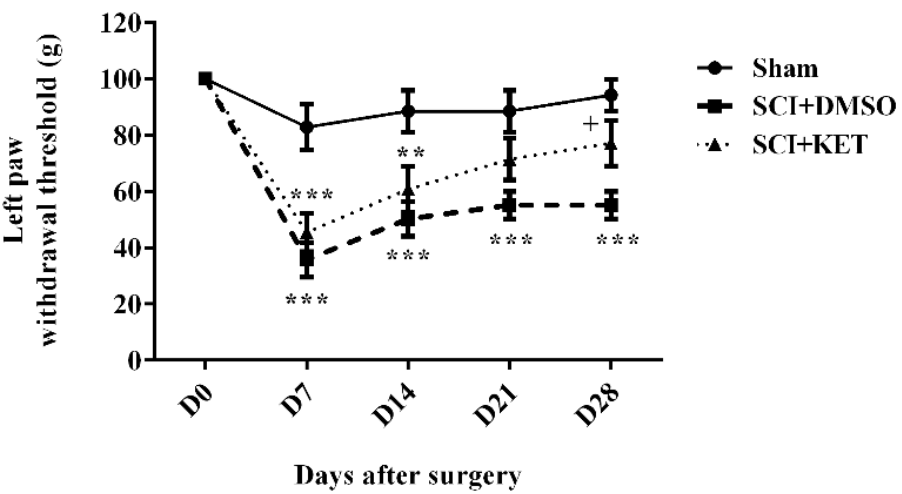

D

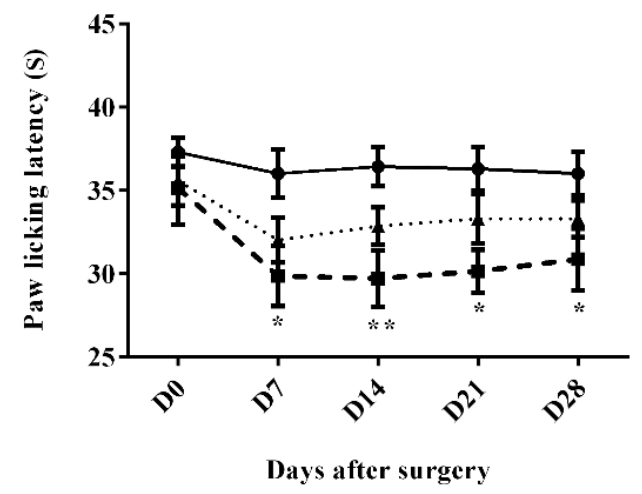

Fig.1. Effects of KET on pain-related behaviors in rats undergoing clip compression SCI. Response thresholds of right hind paw (A) and left hind paw (B) to mechanical stimuli in von Fery test and response threshold to cold and thermal stimuli in the acetone drop test and hot plate test, respectively $(\mathrm{C}$ and $\mathrm{D})$. Data are presented as mean $\pm \mathrm{SEM}(\mathrm{n}=7)$. ${ }^{\prime} P<0.05, "{ }^{\prime} P<0.01$ and ${ }^{* * *} P<0.001$ vs. sham and ${ }^{+} P<0.05,{ }^{++} P<0.01$ and ${ }^{+++} P<0.001$ vs. SCl group. Repeated measures two-way analysis of variance with Bonferroni post-hoc test was used. SCl: spinal cord injury; KET: ketamine $(10 \mathrm{mg} / \mathrm{kg}, 30 \mathrm{~min}$ post-injury); DMSO: dimethyl sulfoxide (as vehicle, 20ul). 
A

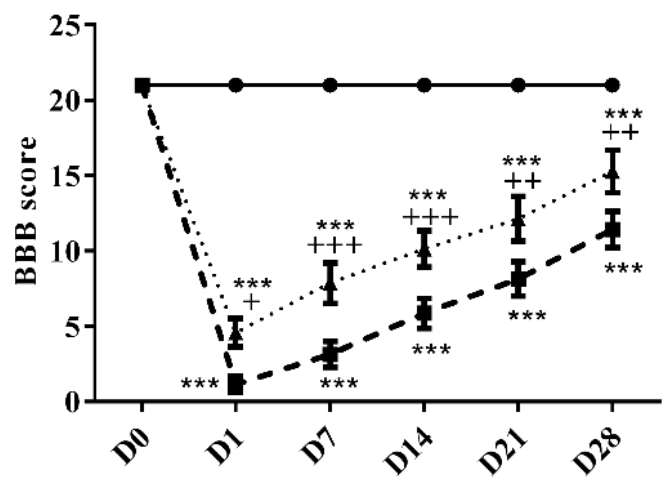

Days after surgery
B

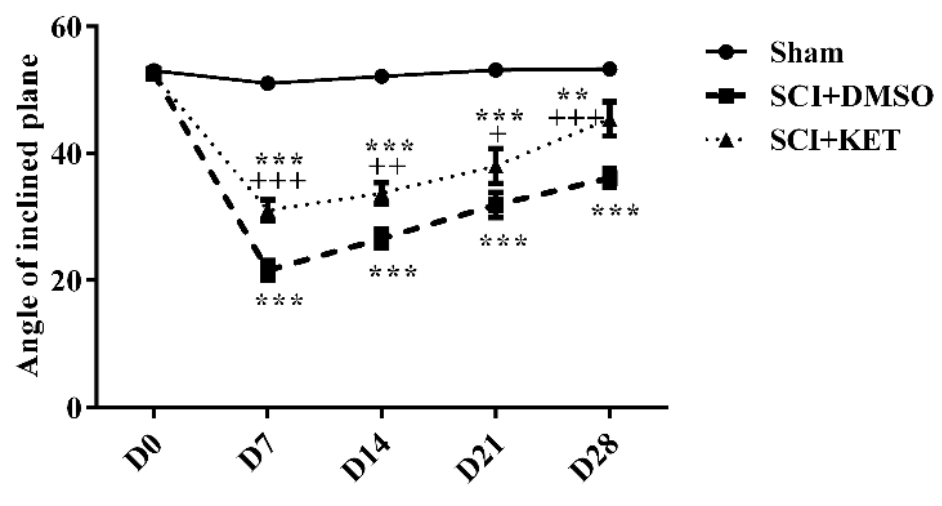

Days after surgery

Fig.2. Effects of KET on motor performance of rats undergoing clip compression SCI. BBB motor score $(\mathrm{A})$ and inclined plane test (B). Data are presented as mean \pm SEM ( $\mathrm{n}=7) .{ }^{* *} P<0.01,{ }^{, * * *} P<0.001$ vs. sham and ${ }^{+} P<0.05,{ }^{++} P<0.01,{ }^{+++} P<0.001$ vs. $\mathrm{SCl}$ group. Repeated measures two-way analysis of variance with Bonferroni post-hoc test was used. SCl: spinal cord

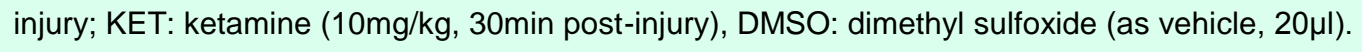

A

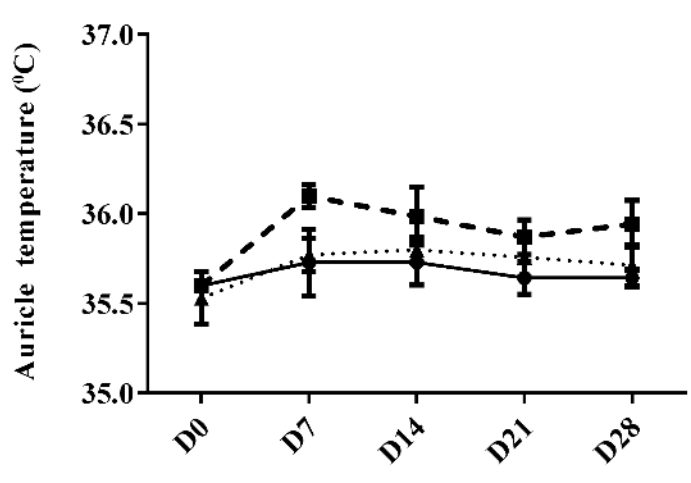

Days after surgery
B

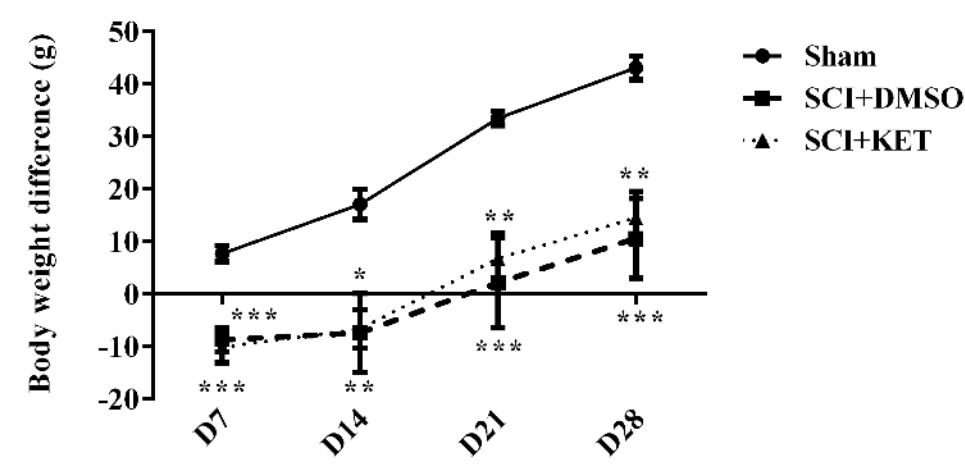

Days after surgery

Fig.3. Effects of KET on body weight and temperature in rats undergoing clip compression SCl. Auricle temperature (A) and body weight differences (B) were measured over a course of 28 days post-injury. Data are presented as mean \pm SEM $(n=7)$. ${ }^{* *} P<0.01, "{ }^{* t *} \mathrm{P}<0.001$ vs. sham group. Repeated measures two-way analysis of variance with Bonferroni post-hoc test was used. SCl: spinal cord injury; KET: ketamine (10mg/kg, 30min post-injury); DMSO: dimethyl sulfoxide (as vehicle, 20ul).

withdrawal response in the sham group in 4 weeks follow-up, $\mathrm{SCl}$ elicited a significant and long-lasting reduction, from day 7 post-injury, in the right and left paw withdrawal threshold which is a sign of mechanical allodynia $(P<0.001)$. The KET treatment group significantly reduced the sign induced by $\mathrm{SCl}$; therefore, from day 21, there was no significant difference in the paw withdrawal threshold between the sham and KET groups (Figs. $1 \mathrm{~A}$ and $\mathrm{B}$ ).

\section{Cold allodynia}

In the evaluation of the cold pain threshold in acetone drop test, two-way repeated-measures ANOVA indicated significant effects of group and time [group:
$\mathrm{F}(2,18)=25.93, P<0.001$, times: $F(4,72)=32.56$, $P<0.001$, and interaction: $F(8,72)=9.208 P<0.001]$. In 4 weeks follow up, rats continued to undergo the normal cold hypersensitivity in the sham group. SCl caused a significant cold hypersensitivity as compared to the sham group. KET improved response to cold stimulation compared to the SCI group. Indeed, from the $3^{\text {rd }}$ week, there was no considerable difference between the sham and KETtreated groups (Fig. 1C).

\section{Heat hyperalgesia}

In the sham group, paw licking latency was almost the same in the entire experiment. Even though SCI 
caused a significant reduction in paw licking latency on the $7^{\text {th }}(P=0.0123)$ and $28^{\text {th }}$ days $(P=0.0465)$ as well, it was seen on the $14^{\text {th }}(P=0.0053)$ and $21^{\text {st }}$ days $(P=0.0123)$. Additionally, in between-group comparison, no considerable difference was observed between SCl and KET-treated groups (Fig. 1D).

\section{Locomotor activity}

Motor behavior was evaluated by BBB scale and inclined plane test following the SCl. Generally, twoway repeated-measures ANOVA for BBB score showed significant effects in groups $[F(2,18)=94.77$, $P<0.001]$, times $[F(5,90)=155.2, P<0.001]$ and interaction $[F(10,90)=40.84 P<0.001]$. Rats in the laminectomy sham group continued to the score 21 showing that no functional impairments occurred during the surgery intrinsically. $\mathrm{SCl}$ resulted in average scores of 0 and 1 on the $1^{\text {st }}$ day post-injury and continued to be different from the sham animals up to day $28^{\text {th }}$ post-injury $(P<0.001)$. The KET treatment enhanced motor function in $\mathrm{SCl}$ rats, especially from the $1^{\text {st }}(P=0.0174)$ to the $28^{\text {th }}$ day $(P=0.0060)$ post-injury, compared to the $\mathrm{SCl}$ group (Fig. 2A).

Two-way repeated measures of ANOVA specified significant effects in group $[F(2,18)=62.30$, $P<0.001]$, time $[F(4,72)=129.9, \quad P<0.001]$ and interaction $[F(4,24)=98.57, P<0.001]$ in the inclined plane test. The same angle stays on the inclined plane apparatus for all intervals in the sham group confirmed that no motor impairments were observed after laminectomy. SCl caused a significant reduced in the mean angle of stay on the inclined-plane apparatus as compared to the sham (Fig. 2B). Though, as shown in the BBB test, $\mathrm{SCl}$ rats indicated a trend of continuous improvement of locomotion during the 4 weeks follow up. Apparently, rats treated with KET significantly caused an increase in the recovery promoting after $\mathrm{SCl}$; therefore, from the $1^{\text {st }}$ week, there was a significant difference between $\mathrm{SCl}$ and KET-treated groups.

\section{Auricle temperature}

In total, the two-way repeated measures of ANOVA indicated significant effects of the groups $[F(2,18)=$ 7.451, $P=0.0044]$, times $[F(4,72)=3.095, P=0.0208]$ and interaction $[\mathrm{F}(8,72)=.4648, \quad P=0.8769]$ on auricular body temperature. SCl elicited a slight increase in the body temperature measured on the $7^{\text {th }}$ day post-injury (which was not significant) in comparison to day 0, before the injury. Nevertheless, between-group comparisons presented no significant differences between the sham, SCl and KET-treated animals (Fig. 3A).

\section{Weight differences}

Based on monitoring animals' weight alterations during 4 weeks post-surgery/injury follow up, two-way repeated-measures ANOVA showed significant effects (groups: $[F(2,18)=11.64, P<0.001]$, times $[F(3,54)=61.88, P<0.001]$ and interaction $[F(6,54)=$ 2, $P=0.0816])$. There was a pattern of normal weight gain in the sham group through the 4 weeks follow up. Weight loss was observed in $\mathrm{SCl}$ at the $1^{\text {st }}$ two weeks post-injury and significantly disrupted weight gain compared to the sham group on the $14^{\text {th }}$ $(P=0.0078), 21^{\text {th }}$ and $28^{\text {th }}$ days $(P<0.001)$. The KET treatment did not prevent weight loss post-injury (Fig. 3B).

\section{Discussion}

In our data, KET attenuated the mechanical and cold pain-related behavior, which were evaluated by von Frey and acetone drop test and provoked a better recovery in the motor function of $\mathrm{SCl}$ animals examined by BBB and inclined plane tests. These effects of KET which started within the first week and continued into the 4 weeks, were long-lasting. KET also led to a mild (not significant) fall in the body temperature with no significant changes in the $\mathrm{SCl}$ induced weight loss.

Contusion, hemisection and compression are mostly used in animal models of SCl-induced sensory-motor dysfunctions. They are considered as the clinical situations of SCl. Clip compression is usually preferred to assess $\mathrm{SCl}$-induced neuropathic pain since it could precisely control the injury rate (Cheriyan et al., 2014). Chronic pain, as a problem in clinical practice for $\mathrm{SCl}$, has a great importance in clinical research. In the current study, post-injury IT KET treatment significantly ameliorated mechanical and cold allodynia. On the other hand, it could not improve heat hyperalgesia which was in line with a randomized, double-blind, crossover study, revealing that IV KET reduced evoked and continuous pain; nonetheless, it could not relieve heat pain following SCI (Eide et al., 1995). In another randomized 
double-blind study, IV KET showed a dosedependent reduction in stroking pain scores where a significant decline was observed in the von Frey hyperalgesia (Leung et al., 2001). Apparently, IV KET also reduced allodynia (Kim et al., 2013) and showed a significant analgesic effect assessed via a visual analogue scale in patients with post-SCI neuropathic pain (Kvarnström et al., 2004). In complex regional pain syndrome type 1 , KET infusion reduced pain significantly in the patients (Sigtermans et al., 2009). Bennet et al. (2000) reported that IT administration of non-NMDA or NMDA glutamate receptor antagonist decreased mechanical allodynia; however, it could not mitigate thermal hyperalgesia in a rat model of SCl-induced pain, which is similar to our data.

In addition to IT and IV routes, KET may be administrated by other routes including SC, transdermal, intranasal, IP, oral and topical (Bell and Kalso, 2018). Oral and topical usage of KET was also effective in reducing various neuropathic pain syndromes (Rigo et al., 2017). In a rat model of segmental spinal nerve ligation, IT compared to IP KET revealed a more and long-lasting withdrawal threshold assessed by von Frey and acetone drop tests (Burton et al., 1999). Further, a meta-analysis showed that KET analgesic effect persists for at least 4 weeks (Niesters et al., 2014), which was in line with the long-lasting impact of KET in our study. Despite the long-lasting effects of IT KET on sensory-motor dysfunction, Doncheva et al. (2019) found that 14-day IP injection of KET showed an early and short-lasting analgesic effect in a rat model of sciatic nerve ligation as evaluated by formalin, analgesia-meter and hot plate tests. In the current study, pain and motor performance were assessed from the $7^{\text {th }}$ day to $28^{\text {th }}$ day post-injury. Thus, the behavioral changes are completely attributed to the IT KET.

Beyond post-SCI pain and the effects of IT KET on pain, motor dysfunction is another SCl-induced complication that is originally associated with the loss of motor neurons. Thus, neuroprotective treatments have been striving to recover SCl-induced motor dysfunction (Pomeroy et al., 2010). In their study, motor dysfunction was recovered slightly over time among $\mathrm{SCl}$ rats which is consistent with some other reports (Hama and Sagen, 2007). The long-lasting results of a single dose of IT KET proposed that only a short time blocking of the NMDA receptor, reduced glutamate-induced central pain (Burton et al., 1999).
In the mechanistic perspective, NMDAR is widely distributed throughout the spinal cord and performs an essential role in the development of pain. KET is an NMDAR antagonist that has anti-inflammatory functions in traumatic injury models (Loix et al., 2011). Glutamatergic mechanisms are involved in the progress of neuropathic pain, post-SCI pain and neurodegenerative diseases; thus confirming the crucial role of glutamate (Samandari et al., 2019). Apparently, it was responsible for the central sensitization of nociceptive neurons existing in the spinal cord and activation of astrocytes by elevating intracellular ion concentration $\left[\mathrm{Ca}^{2+}\right]$ (Sheldon and Robinson, 2007). On the other hand, glutamate induced neuronal apoptosis through attenuating the activation of caspase- 3 and the expression of Bcl-2 family proteins (Zhang and Bhavnani, 2006).

At the spinal level, KET showed an analgesic effect by down-regulating GFAP expression and inhibiting astrocyte activation (Mei et al., 2009). At high doses, KET also played different roles in the channels and receptors such as antagonism at calcium, potassium and sodium channels. Further, KET played an agonistic role at $\mathrm{Y}$-aminobutyric acid receptor and affected dopamine D2 receptors to provide an analgesic effect (Bell and Kalso, 2018). KET also affected other channels/receptors, including kainate, $\mathrm{Y}$-aminobutyric acid, $\mu$-opioid, muscarinic and monoaminergic receptors, L-type calcium channels, as well as NMDARs (Himmelseher and Durieux, 2005). Glutamatergic signaling and nitric oxide metabolism are interrelated. In this line KET prevented nitric oxide-dependent cyclic guanosine monophosphate and nitric oxide synthesis formation stimulated by glutamate (Sleigh et al., 2014). Also, it interferes with the inflammatory responses in ischemia to reduce the intensity of cerebral injury. In an in vitro study, KET suppressed lipopolysaccharideinduced production of tumor necrosis factor- $\alpha$ (TNFa), interleukin-6 (IL-6) and IL-8, which are downstream signaling pathways of NMDA (Kawasaki et al., 1999). It has also been suggested that KET reduced NMDAR type 1 and blocked intracellular protein kinase $A, P K C$ or interconnected pathways to show analgesic effects (Mei et al., 2010).

From the stereochemical point of view, KET has two isomers of $(R)$ and $(S)$. An in vitro study on rat hippocampal-glutamate exposed neurons demonstrated that (S) and racemic attenuated neuron 
injury; however, (R)-KET could not attenuate neuronal damage. Neuroregenerative activities were attained with (S), but not with racemic or (R)-KET (Himmelseher et al., 1996). KET reduced the amount of hemorrhagic necrosis and improved the neurologic severity score following a head trauma in rats (Shapira et al., 1992). In a rabbit model with spinal cord ischemia-reperfusion injury, KET indicated a potent protective effect through reducing malondialdehyde and elevating superoxide dismutase in the spinal cord tissue. The data for the treatment of neuropathic pain by KET has been also derived from clinical reports on the management of nerve injury in oncologic diseases (Domino, 2010). For instance, KET induced a dose-dependent analgesic effect in patients who suffered from morphine-resistant cancer pain. Further, studies have investigated the effects of KET on complex regional pain syndrome (Schwartzman et al., 2009). In a clinical trial, KET also mitigated post-herpetic neuralgia (Sawynok and Zinger, 2016). Besides, IV KET reduced post-injury pain and improved allodynia plus hyperalgesia in two randomized double-blind placebo control studies, in patients with neuropathic pain (Backonja et al., 1994). KET also showed a neuroprotective effect on the injured spinal cord via lowering IL-6, TNF- $\alpha$ and malondialdehyde levels in rats (Tang et al., 2015). A decline in cytokines possibly results in a slight reduction in the term that KET compared to the SCI group caused a slight (but not significant) decrease in the temperature of the body, as observed. (S)-KET is histopathologically as productive as methylprednisolone in preventing secondary SCI. It has been found that KET is even more effective than methylprednisolone in reducing lipid peroxidation levels in the subacute stage of $\mathrm{SCl}$ in rats (Kose et al., 2012). As Hijazi et al. (2003) reported, epidural injected KET was considered as a safe adjunct in $\mathrm{SCl}$-induced chronic pain patients limited to 30 days post-injection which highlighted the importance of the routes of KET administration to show anti-nocifensive effects.

As another complication post-SCI, weight loss occurs due to bone mineral lost, muscle atrophy and metabolism changes in humans (Bauman and Cardozo, 2015). In rodent SCl models, homeostatic mechanisms in later stages, permanent changes in the gastrointestinal tract and hypoplasia at early stages were the main reasons for weight loss (Gefen,
2014). In our study, KET did not attenuate the SCIinduced weight loss during 4 weeks in the context of $\mathrm{SCl}$. This may be due to the reason that KET did not affect the mechanisms involved in weight gain.

\section{Conclusion}

Conclusively, the findings of the present study suggest that KET can be applied as an option in clinical applications to improve sensory-motor dysfunction following $\mathrm{SCl}$. Further investigations focusing on the dose-response and molecular effects of KET are required to show the exact mechanism, safety and the therapeutic value of intrathecal KET in $\mathrm{SCl}$ models.

\section{Acknowledgments}

The current research did not receive any specific grant from funding agencies in the public, commercial or not-for-profit sectors.

\section{Conflict of interest}

The authors stated no conflicts of interest

\section{References}

Backonja M, Arndt G, Gombar KA, Check B, Zimmermann M. Response of chronic neuropathic pain syndromes to ketamine: a preliminary study. Pain 1994; 56: 51-7. https://doi.org/10.1016/03043959(94)90149-X

Bauman WA, Cardozo CP. Osteoporosis in individuals with spinal cord injury. PM R 2015; 7: 188-201. https://doi.org/10.1016/j.pmrj.2014.08.948

Bell RF, Kalso EA. Ketamine for pain management. Pain Rep 2018; 3: e674. https://doi.org/10.1097/ PR9.0000000000000674

Bennett AD, Everhart AW, Hulsebosch CE. Intrathecal administration of an nmda or a nonnmda receptor antagonist reduces mechanical but not thermal allodynia in a rodent model of chronic central pain after spinal cord injury. Brain Res 2000; 859: 72-82. https://doi.org/10.1016/S00068993(99)02483-X

Burton AW, Lee DH, Saab C, Chung JM. Preemptive intrathecal ketamine injection produces a longlasting decrease in neuropathic pain behaviors in a rat model. Reg Anesth Pain Med 1999; 24: 20813. https://doi.org/10.1097/00115550-19992403000005

Cheriyan T, Ryan DJ, Weinreb JH, Cheriyan J, Paul JC, Lafage $V$, et al. Spinal cord injury models: a 
review. Spinal cord 2014; 52: 588-95. https://doi.org/10.1038/sc.2014.91

Domino EF. Taming the ketamine tiger. 1965. Anesthesiology 2010; 113: 678-84. https://doi.org/ 10.1097/ALN.0b013e3181ed09a2

Doncheva ND, Vasileva L, Saracheva K, Dimitrova D, Getova D. Study of antinociceptive effect of ketamine in acute and neuropathic pain models in rats. Adv Clin Exp Med 2019; 28: 573-579. https://doi.org/10.17219/acem/94143

Eide PK, Stubhaug A, Stenehjem AE. Central dysesthesia pain after traumatic spinal cord injury is dependent on n-methyl-d-aspartate receptor activation. Neurosurgery 1995; 37: 1080-7. https://doi.org/10.1227/00006123-19951200000007

Fakhri S, Dargahi L, Abbaszadeh F, Jorjani M. Astaxanthin attenuates neuroinflammation contributed to the neuropathic pain and motor dysfunction following compression spinal cord injury. Brain Res Bull. 2018; 143: 217-224. https://doi.org/10.1016/j.brainresbull.2018.09.011

Fakhri S, Dargahi L, Abbaszadeh F, Jorjani M. Effects of astaxanthin on sensory-motor function in a compression model of spinal cord injury: involvement of erk and akt signalling pathway. Eur J Pain 2019; 23: 750-764. https://doi.org /10.1002/ejp.1342

Gefen A. Tissue changes in patients following spinal cord injury and implications for wheelchair cushions and tissue loading: a literature review. Ostomy Wound Manag 2014; 60: 34-45.

Hama A, Sagen J. Behavioral characterization and effect of clinical drugs in a rat model of pain following spinal cord compression. Brain Res 2007; 1185: 117-28. https://doi.org/10.1016 /j.brainres.2007.09.013

Hijazi Y, Bodonian C, Bolon M, Salord F, Boulieu R. Pharmacokinetics and haemodynamics of ketamine in intensive care patients with brain or spinal cord injury. Br J Anaesth 2003; 90: 155-60. https://doi.org/10.1093/bja/aeg028

Himmelseher S, Durieux ME. Ketamine for perioperative pain management. Anesthesiology 2005; 102: 211-20. https://doi.org/10.1097/ 00000542-200501000-00030

Himmelseher S, Pfenninger E, Georgieff M. The effects of ketamine-isomers on neuronal injury and regeneration in rat hippocampal neurons. Anesth Analg 1996; 83: 505-12. https://doi.org /10.1213/00000539-199609000-00011

Kawasaki T, Ogata M, Kawasaki C, Ogata J, Inoue Y, Shigematsu A. Ketamine suppresses proinflammatory cytokine production in human whole blood in vitro. Anesth Analg 1999; 89: 6659. https://doi.org/10.1213/00000539-19990900000024

Kim K, Mishina M, Kokubo R, Nakajima T, Morimoto $\mathrm{D}$, Isu $\mathrm{T}$, et al. Ketamine for acute neuropathic pain in patients with spinal cord injury. J Clin Neurosci 2013; 20: 804-7. https://doi.org /10.1016/j.jocn.2012.07.009

Kose EA, Bakar B, Ayva SK, Kilinc K, Apan A. Neuroprotective effects of racemic ketamine and (s)-ketamine on spinal cord injury in rat. injury 2012; 43: 1124-30. https://doi.org/10.1016/ j.injury.2012.02.022

Kvarnström A, Karlsten R, Quiding H, Gordh T. The analgesic effect of intravenous ketamine and lidocaine on pain after spinal cord injury. Acta Anaesthesiol Scand 2004; 48: 498-506. https://doi.org/10.1111/j.1399-6576.2003.00330.x

Leung A, Wallace MS, Ridgeway B, Yaksh T. Concentration-effect relationship of intravenous alfentanil and ketamine on peripheral neurosensory thresholds, allodynia and hyperalgesia of neuropathic pain. Pain 2001; 91: 177-87. https://doi.org/10.1016/S0304-3959(00) 00433-4

Loix S, De Kock M, Henin P. The anti-inflammatory effects of ketamine: state of the art. Acta Anaesthesiol Belg 2011; 62: 47-58.

Mei X, Wang W, Wang W, Li Y, Zhang H, Wu S, et al. Inhibiting astrocytic activation: a novel analgesic mechanism of ketamine at the spinal level? J Neurochem 2009; 109: 1691-700. https://doi.org/ 10.1111/j.1471-4159.2009.06087.x

Mei XP, Wang W, Wang W, Zhu C, Chen L, Zhang T, et al. Combining ketamine with astrocytic inhibitor as a potential analgesic strategy for neuropathic pain. Ketamine, astrocytic inhibitor and pain. Mol Pain 2010; 6: 50. https://doi.org/10.1186/17448069-6-50

Mestre C, Pélissier T, Fialip J, Wilcox G, Eschalier A. $A$ method to perform direct transcutaneous intrathecal injection in rats. J Pharmacol Toxicol Methods 1994; 32: 197-200. https://doi.org/ 10.1016/1056-8719(94)90087-6

Niesters M, Martini C, Dahan A. Ketamine for chronic pain: risks and benefits. $\mathrm{Br} J$ Clin Pharmacol 2014; 77: 357-67. https://doi.org/10.1111/bcp. 12094

Pomeroy IM, Jordan EK, Frank JA, Matthews PM, Esiri MM. Focal and diffuse cortical degenerative changes in a marmoset model of multiple sclerosis. Mult Scler 2010; 16: 537-48. 
https://doi.org/10.1177/1352458509360362

Radvansky BM, Puri S, Sifonios AN, Eloy JD, Le V. Ketamine-a narrative review of its uses in medicine. Am J Ther 2016; 23: e1414-e1426. https://doi.org/10.1097/MJT.0000000000000257

Rigo FK, Trevisan G, Godoy MC, Rossato MF, Dalmolin GD, Silva MA, et al. Management of neuropathic chronic pain with methadone combined with ketamine: a randomized, double blind, active-controlled clinical trial. Pain Physician 2017; 20: 207-215.

Samandari R, Hassanpour-Ezatti M, Fakhri S, Abbaszadeh F, Jorjani M. Sex differences and role of gonadal hormones on glutamate level after spinal cord injury in rats: A microdialysis study. Basic Clin Neurosci 2019; 10: 225-34. https://doi.org/10.32598/bcn.9.10.260

Sawynok J, Zinger C. Topical amitriptyline and ketamine for post-herpetic neuralgia and other forms of neuropathic pain. Expert Opin Pharmacother 2016; 17: 601-9. https://doi.org $/ 10.1517 / 14656566.2016 .1146691$

Schwartzman RJ, Alexander GM, Grothusen JR, Paylor T, Reichenberger E, Perreault $M$. Outpatient intravenous ketamine for the treatment of complex regional pain syndrome: a double-blind placebo controlled study. PAIN 2009; 147: 107-15. https://doi.org/10.1016/j.pain.2009.08.015

Shapira Y, Artru AA, Lam AM. Ketamine decreases cerebral infarct volume and improves neurological outcome following experimental head trauma in rats. J Neurosurg Anesthesiol 1992; 4: 231-40. https://doi.org/10.1097/00008506-19921000000001

Sheldon AL, Robinson MB. The role of glutamate transporters in neurodegenerative diseases and potential opportunities for intervention. Neurochem Int 2007; 51: 333-55. https://doi.org/ 10.1016/j.neuint.2007.03.012

Siddall PJ, Middleton JW. Spinal cord injury-induced pain: mechanisms and treatments. Pain Manag 2015; 5: 493-507. https://doi.org/10.2217/pmt.15 .47

Sigtermans MJ, Van Hilten JJ, Bauer MC, Arbous MS, Marinus J, Sarton EY, et al. Ketamine produces effective and long-term pain relief in patients with complex regional pain syndrome type 1. Pain 2009; 145: 304-11. https://doi.org/ 10.1016/j.pain.2009.06.023

Sleigh J, Harvey M, Voss L, Denny B. Ketamine-More mechanisms of action than just NMDA blockade. Trends Anaesth Crit care 2014; 4: 76-81. https://doi.org/10.1016/j.tacc.2014.03.002

Tang SH, Yu JG, Li JJ, Sun JY. Neuroprotective effect of ketamine on acute spinal cord injury in rats. Genet Mol Res 2015; 14: 3551-6. https://doi.org/10.4238/2015.April.17.4

Walker SM, Westin BD, Deumens R, Grafe M, Yaksh $T L$. Effects of intrathecal ketamine in the neonatal ratevaluation of apoptosis and long-term functional outcome. Anesthesiology 2010; 113: 147-59. https://doi.org/10.1097/ALN.0b013e3181 dcd71c

Zhang Y, Bhavnani BR. Glutamate-induced apoptosis in neuronal cells is mediated via caspasedependent and independent mechanisms involving calpain and caspase- 3 proteases as well as apoptosis inducing factor (aif) and this process is inhibited by equine estrogens. BMC Neurosci 2006; 7: 49. https://doi.org/10.1186/1471-2202-749

Zhou HY, Chen SR, Pan HL. Targeting n-methyl-daspartate receptors for treatment of neuropathic pain. Expert Rev Clin Pharmacol 2011; 4: 379-88. https://doi.org/10.1586/ecp.11.17 